\title{
COMPRENDER LA VIOLENCIA, PREVENIR LA VIOLENCIA: RETOS PARA EL TRABAJO SOCIAL.
}

\author{
HORTENSIA REDERO BELLIDO \\ BEGOÑA SAN MIGUEL DEL HOYO \\ E.U. Trabajo Social. Universidad de Alicante.
}

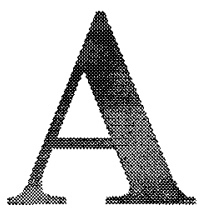

sípues, encontramos tres causas principales de riña en la naturaleza del hombre. Primero: competición; segundo, inseguridad; tercero, gloria.

El primero hace que los hombres invadan por ganancia; el segundo, por seguridad; y el tercero, por reputación. Los primeros usan de la violencia para hacerse dueños de las personas, esposas, hijos y ganado de otros hombres; los segundos para defenderlos; los terceros, por pequeñeces, como una palabra, una sonrisa, una opinión distinta, y cualquier otro signo de subvaloración, ya sea directamente de su persona, o por reflejo de su prole, sus amigos, su nación, su profesión o su nombre.

Hobbes, 1979: 224.

Precisamente lo imperativo del mandamiento "No matarás" nos da la certeza de que somos del linaje de una serie interminable de generaciones de asesinos que llevaban en la sangre el gusto de matar, como quizá lo llevemos todavía nosotros. Las aspiraciones éticas de la humanidad, cuya fuerza e importancia no hace falta andar criticando, son una conquista de la historia humana; y han devenido después, en medida por desdicha muy variable, el patrimonio heredado de la humanidad que hoy vive.

Freud, 1995: 297.

Después de haber escapado de lo sagrado más ampliamente que las demás sociedades, hasta el punto de "olvidar" la violencia fundadora, de perderla por completo de vista, nos disponemos a reencontrarla; la violencia esencial regresa a nosotros de manera espectacular, no sólo en el plano de la historia sino en el plano del saber. Este es el motivo de que esta crisis nos invite, por primera vez, a violar el tabú que ni Heráclito ni Eurípides, a fin de cuentas, han violado, a dejar por completo de manifiesto, bajo una luz perfectamente racional, el papel de la violencia en las sociedades humanas. 


\section{CONSIDERACIONES PREVIAS.}

\subsection{Violencia individual y violencia social.}

La cita de estos textos clásicos sobre la violencia, escritos desde muy distintas perspectivas, tiene por finalidad ahorrarnos una larga digresión, que, sin embargo, parece necesaria al inicio de nuestra reflexión, acerca de la consideración de la violencia. Se trata de establecer que la dificultad de abordar el tema de la violencia surge de su carácter central en la constitución de las sociedades -y, en consecuencia, en cierta medida, inevitable-, de su universalidad histórica, de la diversidad de sus manifestaciones y de su carácter al mismo tiempo individual y colectivo, humano y social. No es extraño, entonces, que las grandes reflexiones modernas sobre la violencia hayan tratado de integrar naturaleza humana y orden social, bien atribuyendo al orden social el comportamiento agresivo de los individuos y los grupos, bien fundamentando la violencia social sobre una psicología de los instintos o las pasiones.

Conceptualizada por la filosofía clásica, representada simbólicamente por la tragedia griega, la violencia es teóricamente eludida hasta la Modernidad. La reflexión moderna sobre la violencia es resultado de la preocupación por el nuevo orden y la búsqueda de referentes y bases para su instauración: hablar de violencia es, en adelante, hablar del contrato social. Enseguida, primero con Hegel y después con Marx y Engels, la violencia es valorizada como fuerza de cambio social y teorizada como violencia revolucionaria. La reflexión freudiana es un intento de establecer los nexos entre la violencia individual y social. Los desastres de las dos guerras y la violencia esencial de los totalitarismos volvieron la violencia al centro de las preocupaciones y se tradujeron en nuevas elaboraciones, sobre todo desde la filosofía. A partir de los años sesenta, con el estallido de una nueva conflictividad social, la aparición en escena del terrorismo y el crecimiento de la delincuencia, la violencia reaparece como una categoría siempre presente, pero difusa, que va a dar lugar a muy diversas aproximaciones.

Los intentos por categorizar la violencia han tendido a diluir su significado al ampliarla hasta una diversidad de formas y manifestaciones que incluyen ahora no sólo las clásicas distinciones entre privada y colectiva, sino también otras como: física o simbólica; política, social, económica o ecológica; personalizada o impersonal (institucional y técnica); racional o anómica y gratuita; real o representada; etc. Cabe pensar que esta polisemia no es sólo el resultado de las pugnas teóricas por imponer definiciones, ni siquiera de los múltiples puntos de vista disciplinares desde los que ha sido abordada, sino que surge de su ca- 
rácter de "fenómeno social total", en expresión que Imbert (1992) toma de Mauss, y de las dificultades para establecer delimitaciones estrictas en ese continuo que configuran las formas de dominación social.

No es éste el lugar de elucidar cuestiones tan complejas. Para nuestros propósitos, basta con afirmar que la violencia es consustancial a los individuos y a las sociedades. Consustancial a los individuos, porque forma parte del complejo sistema psicológico y relacional de la conducta humana; y porque los hombres son capaces no sólo de reaccionar violentamente ante la percepción de la amenaza o en defensa de sus intereses, sino también de "usar estratégicamente la violencia" (Ramoneda, 2001). Ni siquiera cabe negar, en el estado actual del conocimiento, que sobre el comportamiento violento incidan factores biológicos, siempre que no olvidemos la plasticidad de la conducta humana y su relativa indeterminación biológica. Consustancial a las sociedades, porque, se parta de una concepción más o menos conflictiva del orden social, toda reflexión sobre la sociedad incorpora necesariamente la noción de conflicto social, y la violencia como un recurso permanente del conflicto. Ninguna teoría sobre el orden social puede evitar la reflexión sobre el poder y la dominación.

Se mire entonces a uno u otro de los rostros de este Jano amenazante, la reflexión sobre la violencia es necesariamente pesimista, porque es una reflexión sobre el mal y la imposibilidad de combatirlo. Por otra parte, la ubicuidad de la violencia y su carácter central abren necesariamente, en ésta y en cualquier época, el debate sobre su legitimidad, un debate donde la ética y la política se mueven siempre en terrenos resbaladizos y se encuentran con límites imprecisos. Al mismo tiempo, el espectáculo de la violencia, por más que la inteligencia la asiente sobre sólidas bases, resulta intolerable para una gran parte de nosotros, una amenaza no sólo sobre nuestras vidas y las vidas ajenas, sino también sobre la posibilidad misma de construir un mundo más habitable.

\subsection{La consideración social de la violencia.}

Si resulta sencillo aceptar que la violencia no es un producto exclusivamente social, consideramos, sin embargo, que es legítimo un análisis estrictamente social de la violencia, y ello por varios motivos. En primer lugar, porque no cabe pensar en una "naturaleza humana" indeterminada y preexistente a lo social; y, si existiera algo así, no sería cognoscible, puesto que no conocemos más que seres sociales, conformados socialmente y que se actúan en contextos sociales determinados, que ponen límites a los comportamientos y a las formas de concebir los propios comportamientos. En ese sentido toda la violencia es 
social, pues se desenvuelve en escenarios necesariamente sociales y se dirige a objetos también sociales, utilizando mecanismos socialmente aprendidos.

La violencia es social, en segundo lugar, porque la sociedad tiene un carácter esencialmente violento. Si hacemos caso a René Girard, la sociedad se ha visto confrontada desde el origen al tratamiento de la violencia en un doble sentido: ha buscado permanentemente mecanismos para defenderse de la violencia destructiva, como amenaza a la propia supervivencia de la sociedad, y ha incorporado la violencia en las formas de control de la violencia, a través de la legitimación de ciertas formas de dominio o de normas capaces de evitar la violencia mediante el uso mismo de la fuerza, dando cauces sociales a la violencia, por ejemplo, a través de la víctima propiciatoria, el chivo expiatorio, el no hombre, el extranjero. La Sociología ha oscilado, dado su gusto por el dualismo, entre la concepción conflictiva o consensualista del orden social. No es preciso apostar por ninguna de las posiciones a las que parece obligarnos la disyuntiva clásica, más bien cabe pensar que todas las sociedades conocidas se construyen sobre la cooperación y la lucha en dosis históricamente cambiantes.

En tercer lugar, la violencia es social no sólo porque es engendrada por las condiciones sociales, sino porque toda sociedad es necesariamente ambigua frente a la violencia: controla, a través de distintos mecanismos, ciertas formas de violencia, mientras admite otras, legitimando su uso formal o informalmente. Así, en determinados casos, la violencia se configura como una estrategia-si no siempre lícita, sí admitida- para imponer prerrogativas o defender derechos que no podrían lograrse mediante otros mecanismos como el recurso a la concertación. Es la sociedad quien otorga la validez a las estrategias violentas y por tanto permite su desarrollo. Estas formas de violencia -como la guerra, como la violencia estructural, como la violencia de género- engendran las propias condiciones de su reproducción porque son los medios más sencillos para lograr los fines del sometimiento, la dominación o la extorsión del otro. Cabe hablar por tanto de violencia estratégica cuando su reproducción y mantenimiento dependen de su aceptación social, implícita o explícitamente, que valida así el uso de la fuerza. La idea de Freud de una pugna inmemorial entre una cultura, que trata de controlar la violencia, frente a unas pulsiones, cuya inhibición es fuente de neurosis, no daría suficiente cuenta de esta ambigüedad esencial del tratamiento social de la violencia.

Más allá, y aunque aquí quepa discutir la utilización del termino violencia como sinónimo de poder o de dominación, es preciso considerar la dificultad para establecer los límites entre la "violencia material" -en cierto sentido la única violencia-, y la "violencia simbólica", por 
utilizar la expresión de Bourdieu. Ha sido Foucault el autor que con más precisión se ha ocupado de ese poder capilar y de los mecanismos visibles e invisibles sobre los que se cimenta: "La humanidad no progresa lentamente, de combate en combate, hasta una reciprocidad universal en la que las reglas sustituirán para siempre a la guerra; instala cada una de estas violencias en un sistema de reglas y va así de dominación en dominación" (1980: 17). El poder no puede ser exclusivamente represivo, no puede apoyarse sobre el uso exclusivo de la fuer$\mathrm{za}$, si quiere lograr la obediencia o la aquiescencia de los dominados.

Bourdieu, muy cercano en esta materia a Foucault, se refiere a lo largo de toda su obra a esa violencia no violenta que moldea la acción y el pensamiento a través del habitus, inscribiéndose en los cuerpos y las mentes, y naturalizando así la dominación $(1999,2000)$. El poder no se sostiene sólo mediante la violencia o la represión, sino que lo hace sobre todo dando forma a nuestros deseos, convirtiendo a la víctima en cómplice del verdugo. El pensamiento feminista ha permitido ampliar la perspectiva sobre la violencia y el ejercicio de la dominación hacia estos campos porque, ineludiblemente, ha tenido que plantear la cuestión del sostenimiento del sistema patriarcal a lo largo de toda la historia. Como mantiene J. Benjamin: "(...) ésta ha sido una debilidad de la política radical: idealizar a los oprimidos, como si la política y la cultura de éstos nunca hubieran sido alcanzadas por el sistema de dominación, como si las personas no participaran en su propia sumisión. Reducir la dominación a una relación simple de agente y paciente equivale a reemplazar el análisis por la indignación moral" (1998: 14).

\subsection{La percepción social de la violencia.}

Resulta difícil establecer si estamos asistiendo a un crecimiento real de la violencia hoy. Una afirmación como ésta, por sus consecuencias, requeriría de complejos análisis empíricos que la confirmaran. Podemos, sin embargo, establecer dos hechos sobre la percepción social de la violencia. En primer lugar, la violencia se hace al mismo tiempo más visible y más opaca. Más visible, porque ocupa una parte de los medios de comunicación y forma parte esencial del espectáculo mediático, que igual se detiene en el apocalipsis de las Torres Gemelas, en la guerra retransmitida en directo o en el asesinato de niños. Más opaca, porque el espectáculo de la violencia oscurece la comprensión de la violencia, de las violencias, al convertirlas en meras imágenes efímeras e intercambiables, y desvaneciendo cualquier reflexión y cualquier juicio.

Como ha observado Virilio, el hombre "no sólo ha miniaturizado los motores, las máquinas y los procesadores, sino que acaba de volver 
minúscula la guerra (...) el hombre de la posmodernidad acaba incluso de reducir el formato de la violencia a su más simple expresión: una imagen" (1997:63). Es ya un hecho admitido que los medios de comunicación, a través de la representación de la realidad, son creadores de realidad: "ya no es el mundo el que se hace imagen, sino el imaginario que se hace mundo" (Imbert, 1992). El problema es que la imagen, progresivamente, parece impedir la mirada, la "visión sin mirada" a la que alude Virilio; o, en contundente expresión de Baudrillard (1991): "una profusión de imágenes en las que ya no hay nada que ver".

En segundo lugar, cabe afirmar que hoy crece el temor a la violencia y el sentimiento generalizado de vivir bajo múltiples amenazas. Y ello, porque tenemos la impresión de vivir en un mundo crecientemente inseguro, inestable, caótico y, sobre todo, incomprensible (Beck, 2001). El miedo se acentúa cuando la realidad se vuelve imprevisible y el peligro inminente, aunque sea en el imaginario, generando un sentimiento de impotencia. Las fuentes de este sentimiento son sin duda múltiples: desde la percibida ingobernabilidad de un mundo en proceso de globalización, hasta la crisis de las identidades definidas (nacionales, sexuales, laborales, etarias), o la pérdida de control sobre la propia vida debida a la discontinuidad biográfica y su imprevisibilidad creciente (Sennett, 2001).

Tenemos además la impresión de que los mecanismos destinados a asegurar el control de la violencia y a protegernos de ella están fallando, que son inservibles y no pueden cumplir su cometido: la familia, la escuela, los lazos comunitarios, los controles sociales informales, los cuerpos de seguridad, la ley, la justicia, son permanentemente puestos en entredicho por su incapacidad para controlar la violencia desde sus distintos niveles de competencia. Todos ellos sufren de la erosión de su legitimidad por la misma visibilidad creciente de la violencia.

La desvalorización de la vida humana, de la ajena y de la propia, en unas zonas del planeta -como ilustran suficientemente las matanzas dirigidas contra ciertas etnias en algunas zonas de África o la disponibilidad permanente para suicidio de los combatientes islámicos-convive con la obsesión securitaria en las sociedades más ricas, que demandan crecientemente el uso de una "violencia legítima" tanto en la escena mundial como en la escena doméstica, en demostración adicional de que también la vida y la muerte están sujetas a consideraciones históricas y sociales cambiantes.

La obsesión securitaria en Occidente, inducida por la visibilidad de la violencia y la pérdida de control sobre las propias condiciones de vida, se manifiesta sintomáticamente bajo múltiples manifestaciones: el temor a la delincuencia y la demanda de endurecimiento policial y penal contra los delincuentes, la creciente desconfianza ante grupos so- 
cialmente excluidos (los habitantes de ciertos barrios, las minorías étnicas, los jóvenes de los estratos sociales más desfavorecidos), la aversión extendida hacia los inmigrantes (utilice o no argumentos racistas), o la demanda de protección pública y privada. En fin, genera sobre todo la expansión de un sentimiento de desconfianza social que alimenta la segregación. Políticamente, se manifiesta en el apoyo a ciertos partidos de ideario xenófobo y ultraderechista, que concitan, mediante la apelación a la violencia y la demanda de seguridad, el apoyo de sectores significativos de la población, un fenómeno que se extiende incluso a países de tradición más liberal, como Holanda.

\section{ALGUNAS FORMAS DE VIOLENCIA.}

Ahora bien, si resulta difícil tanto desentrañar el origen como establecer una definición unívoca de la violencia y dar cuenta de sus múltiples manifestaciones, no es tan difícil aproximarse, como ha planteado este Congreso, a un conjunto de violencias que, desgraciadamente, se manifiestan en nuestras sociedades de manera creciente. No pretendemos ser exhaustivas en su enumeración, ni siquiera justificar su selección por criterios de frecuencia o de gravedad. Se trata, más sencillamente, de reflexionar sobre las expresiones de la violencia que se manifiestan en el ámbito de actuación del Trabajo Social y que, por tanto, implican necesariamente a los trabajadores sociales.

\subsection{Violencia e indefensión social.}

En primer lugar, no es difícil, por ejemplo, ponerse de acuerdo en que los mayores índices de violencia los sufren los sujetos más frágiles, porque ellos se convierten con mayor frecuencia en chivos expiatorios de tensiones psicológicas y sociales, y porque su indefensión permite el ejercicio contra ellos de la violencia sin graves consecuencias para quien la ejerce. Podríamos entonces concluir que, cuanto más desigual es una sociedad, cuanto más concentrado está el poder en determinados grupos y cuanto más excluidos están otros de los distintos recursos para defenderse, en mayor medida se generaran situaciones de violencia, de esa violencia insoportable porque los que la sufren no pueden defenderse: el niño, la mujer, el pobre, el inmigrante.

Es indudable que en las últimas décadas los sectores sociales más frágiles, por su menor participación en los beneficios económicos, sociales y culturales, han tendido a crecer y, sobre todo, ha aumentado la distancia que los separa de los que obtienen mayores beneficios. Pero no se trata meramente de un aumento de las desigualdades sociales. El 
concepto de exclusión social, como el de dualización antes, han tratado de dar cuenta de una realidad nueva, de una situación social cualitativamente distinta de la vieja noción de pobreza. Se trata de la formación de una auténtica frontera social entre la clase mayoritaria y aquéllos que, por usar la expresión de Dahrendorf (1998), son "expulsados del edificio de la ciudadanía". La violencia estructural de que son objeto estos sectores necesariamente alimenta las desviaciones y la delincuencia, que desencadenan a su vez una exigencia de violencia legal para controlarlas.

Loï Waquant (2000) ha descrito con detalle el proceso de "fortalecimiento del Estado Penal", bajo la fórmula de "tolerancia cero" de origen norteamericano. La desaparición del Estado económico y la reducción del Estado social, dice Waquant, corren necesariamente parejas con el reforzamiento de este Estado penal. Quienes glorifican y apelan al reforzamiento del Estado en esta materia son los mismos que propugnan la desaparición de las otras caras del Estado. Pero esta opción no es una incongruencia, bien al contrario, la penalización masiva es la consecuencia necesaria del retroceso del Estado, el único mecanismo capaz de oponerse a la lógica de la dualización social y el crecimiento de la exclusión. En la época de la desocupación y del empleo precario, en el periodo de la inseguridad social instituida, se hace necesario un nuevo dispositivo de gestión de la miseria: "mano invisible del mercado y mano de hierro del Estado".

La tolerancia cero ha llegado a los medios de comunicación españoles poco después de que el libro en Waquant nos diera a conocer la genealogía de esta formula acuñada en Estados Unidos y muy bien recibida en Europa, sobre todo en el Reino Unido, pero también en Francia o Alemania. Demanda de tolerancia cero frente a una elevación significativa de los delitos que debe traducirse, sin ninguna duda, en una mayor eficacia policial y el consecuente aumento de la población reclusa. El único problema es que ya antes de que estas nuevas políticas empiecen a aplicarse, la población reclusa en España ha ido creciendo a un ritmo sostenido los últimos años, lo que nos ha permitido gozar del dudoso privilegio de tener, con la salvedad del Reino Unido, la mayor población reclusa de Europa: 114 reclusos por cada 100.000 habitantes, frente a 64 de Suecia, 61 de Dinamarca o 52 de Finlandia.

Foucault había ya avanzado en los años setenta las líneas de gestión del "nuevo orden interior" (Álvarez Uría, 1989). Sus predicciones se han cumplido sobradamente: el crecimiento de la exclusión social y el retroceso del Estado social han conducido hacia la penalización de la miseria, blanda o dura. La mejor forma de hacer retroceder la prisión sigue siendo, como siempre, termina Waquant, hacer progresar los derechos sociales y económicos, sigue siendo la construcción de un Esta- 
do social europeo digno de ese nombre. En ausencia de cualquier proyecto de integración real, económica y social, para los inmigrantes y para un sector importante de la población autóctona, la única forma de control social es, necesariamente, policial y penal. Desde las mismas instituciones de justicia, algunos jueces y fiscales están recordando estos días al Gobierno y a los ciudadanos que es la exclusión, y no la inmigración, la causa del aumento de los delitos.

\subsection{La violencia contra los próximos.}

Una segunda fuente de violencia, que genera especial preocupación entre los trabajadores sociales como este mismo Congreso ha puesto de relieve y sin duda en la mayoría de los ciudadanos, es la violencia privada, la violencia que se origina en el interior de la familia y que se dirige principalmente contra sus miembros más frágiles: los niños, las mujeres y los ancianos, principalmente. Es posible que esta violencia no haya aumentado, es posible que la creciente preocupación que existe socialmente frente a ella derive de su mayor visibilidad social, porque resulta crecientemente intolerable para quienes la padecen y para los ciudadanos que empiezan a considerarla como violencia y no como el necesario acompañamiento de las relaciones familiares.

Esta forma de violencia resulta especialmente escandalosa no sólo por su incidencia real (más de una cuarta parte de las muertes por violencia se produce entre familiares), sino también por esa mezcla de privacidad y aceptación tácita que ha merecido hasta ahora, y que en cierta medida sigue mereciendo. Sabemos, además, que sus consecuencias son doblemente peligrosas, pues no sólo afectan a quienes la sufren, que pagan con su vida muchas veces, sino también porque reproducen la violencia en los mismos que la soportan, como han demostrado ampliamente los estudios sobre la materia.

Estas formas de violencia han acompañado siempre a la vida familiar -como los abusos sexuales hacia las mujeres y los niños, siempre silenciados-, sólo que formaban parte de lo comúnmente aceptado, la cara semioculta de la noción de disciplina familiar encomendada al cabeza de familia. En sociedad, parece que sólo es posible hablar de lo que se habla. Si ahora los medios de comunicación hablan de ello, las víctimas también pueden empezar a considerarse como tales y a elaborar personal y socialmente su experiencia de víctimas.

Ahora bien, no hay duda de que los cambios estructurales que están afectando a la familia introducen nuevos elementos favorecedores de la violencia. La familia, como se han encargado de poner de relieve todos los estudiosos, es al mismo tiempo una estructura de protección esencial para los individuos, crecientemente aislados en la era de 
desocialización (Lipovetsky, 1994), el refugio último que otorga reconocimiento personal y social, la fuente casi única de realización y el calor social. Al mismo tiempo, la familia se disuelve con mayor frecuencia, su duración es corta (la tasa de divorcio aumenta en todas las sociedades) y los individuos se ven con frecuencia expulsados del cálido refugio. La separación exaspera la violencia, pues el agresor pierde la razón y el objeto de su violencia: la posesión y el control de la víctima. Por eso, no el maltrato, pero sí la muerte es desencadenada con frecuencia por la ruptura.

La violencia aparentemente creciente contra los niños, formando parte de este mismo complejo de relaciones, tiene quizá explicaciones que lo rebasan. La explotación, las agresiones y el abuso sexual de los niños conviven hoy con la tendencia a su máxima protección y cuidado, a su conversión en el centro de las atenciones de los adultos, como otra forma de expansión de su propio derecho a la autorrealización por medio de la maternidad/paternidad (Hurtado, 2001). Los niños, ese bien escaso en Occidente y abundante en los países pobres, son objeto de máximo cuidado o de extorsión económica y sexual, y ambas expresiones forman parte por igual de la consideración social actual de la infancia.

Otro tanto cabría decir de los ancianos. Los ancianos, como las mujeres y los niños, han sido objeto de violencia en el viejo orden de la familia tradicional con más frecuencia de la que se reconoce. La literatura ha suplido algunas veces a la sociología como reveladora de esta violencia. ${ }^{1}$ Pero hoy, no cabe interpretarla como un mero residuo del pasado, en tránsito por tanto de desaparición junto a la familia patriarcal. Por el contrario, junto a las viejas formas de violencia, se expanden otras que derivan de la máxima desprotección de los más frágiles ante la disolución de ese tipo de familia, y del entramado de relaciones y valores que las sostenía.

Bauman plantea lo que parece una paradoja, que el colapso de las antiguas estructuras de autoridad afecta a la integración social en todos los niveles, pero resulta especialmente destacado y tiene especiales consecuencias en dos niveles, el global y de la vida política cotidiana: "Tras el desmantelamiento del modelo panóptico de orden social, en el que las familias patriarcales son la célula fundamental del tejido social y los 'cabezas de familia' masculinos cumplen una función disciplinaria, paralela a la del capataz en las plantas de las fábricas o el sargento en los barracones, las relaciones de género se han convertido

Sólo por citar un ejemplo, Cesare Pavese, en La luna y las hogueras, de reciente publicación en España, deja constancia de estas formas de violencia en las familias campesinas italianas hacia la mitad del siglo XX. Desde la novela picaresca hasta la novela realista y social de los siglos XIX y XX podríamos citar innumerables testimonios. 
también en otro territorio en el que se libran a diario batallas de reconocimiento" (2002: 7).

Las formas de coerción que se practican en la vida familiar, sigue Bauman, que antes se consideraban inevitables y se sufrían en silencio, han perdido o han visto negada su legitimidad cuando han dejado de ser percibidas como inevitables, como "naturales", en una situación de aceptación creciente de la ruptura de relaciones. Sólo parecen admisibles ahora nuevas formas de "relaciones puras" -de cohabitación y compañerismo, carentes de normas establecidas de derechos y obligaciones y libres de cualquier compromiso a largo plazo- "mediante una experimentación continuada y por naturaleza no definitiva, uno de cuyos ingredientes indispensables es la sucesión de batallas" (ibidem).

Así, una vez más, el cambio social se acompaña de convulsiones y desata irremediablemente la violencia, como si la violencia fuera la única "partera de la historia", expresión de Marx que no podemos compartir en lo profundo, pero que cabe aceptar como una buena descripción sintomática.

\subsection{La violencia contra los otros: los inmigrantes.}

Es preciso distinguir la violencia de los inmigrantes de la violencia contra los inmigrantes. La primera forma parte del mismo complejo de violencias que hemos intentado describir. En algunos casos, su mayor proximidad a los márgenes del sistema social y cultural puede favorecer su desviación, pero no en distinta medida que para otros colectivos. Es preciso, además, distinguir la inmigración del fenómeno de la "globalización del delito", y la expansión de viejas y nuevas mafias; organizaciones criminales que, como los capitales, actúan ahora en el ámbito mundial, integrando, en grandes redes, formas muy diversas de delincuencia, de cuello blanco o azul, y una jerarquía de delincuentes que obtienen distintas porciones de la ganancia generada. La presencia de nuevos "delincuentes extranjeros" tiene mucho más que ver con la globalización del capital que del trabajo.

La violencia contra los inmigrantes, que parece en España haber tomado el relevo a la violencia tradicional contra los gitanos sin llegar a sustituirla, se expande rápidamente y amenaza las bases de su posible integración. El análisis de este fenómeno, novedoso aquí, ha ocupado sin embargo desde largo tiempo a los investigadores de otros países que lo han conocido desde antes. Resulta difícil resumir ni siquiera una pequeña parte de las explicaciones y los argumentos esgrimidos, pero vamos a destacar aquí dos cuestiones que nos parecen más significativas.

Por una parte, como recuerda Bauman (2002b), durante doscientos 
años, Occidente ha considerado que los extranjeros (los refugiados, los desplazados, los inmigrantes voluntarios e involuntarios) eran responsabilidad del país de acogida, y como tal se los trataba. Una vez admitidos, se encontraban bajo la jurisdicción exclusiva del país donde llegaban. A partir de ahí, los Estados podían usar dos tipos de medidas: "La primera solución venía a ser 'absorber a los extranjeros'. Bien literalmente, en carne y hueso -como el canibalismo supuestamente practicado por algunas antiguas tribus-, bien en una versión moderna, metafórica, más sublime, de forma espiritual - como en la asimilación asistida por el poder y practicada de forma casi universal por los Estados-nación (...)-. La segunda solución era 'vomitar a los extranjeros' en lugar de devorarlos: reunirlos y expulsarlos o bien fuera de la esfera del poder estatal, o bien fuera del mundo de los vivos". El problema, termina el diagnóstico de Bauman, es que ninguna de estas estrategias está hoy al alcance de los Estados.

La expulsión choca con la visibilidad mediática de la violencia que genera y levanta la protesta de sectores sociales sensibles y organizaciones de derechos humanos. Sólo un gobierno integrado por neofascistas se ha atrevido públicamente a defender su necesidad, aunque prácticamente todos los demás la practiquen en mayor o menor medida y siempre subrepticiamente. Por otra parte, la integración no forma ya parte de los planes de los países receptores, ni de sus gobiernos ni de la mayoría de sus ciudadanos. Cabe pensar incluso que ni siquiera sea posible, al menos bajo su forma tradicional de asimilación. La inmigración es valorada y soportada exclusivamente por su carácter de mano de obra disponible para la realización de ciertas tareas en ciertos sectores. Mano de obra barata y disciplinada, utilizable, sustituible y desechable al compás del irregular ritmo de crecimiento de nuestras economías.

Su integración real, más allá de las palabras pronunciadas para su circulación en los medios de comunicación, preocupa tan poco como la disolución más amplia del tejido social y los fenómenos de desocialización que han generado las tendencias ya descritas. Desviar hacia las diferencias culturales la responsabilidad de su falta de integración, como si las culturas acabaran de inventarse justo en esta fase de relativamente débiles flujos migratorios, es la última apuesta para cerrar el debate de la integración económica y social.

Es ahí donde se genera la violencia contra los inmigrantes, en ese proyecto de integración débil que los ciudadanos acaban por percibir como amenaza latente a su propia seguridad. Desconfiamos de los inmigrantes no sólo porque son extranjeros, no sólo porque son extraños, sino porque sabemos que seguirán siéndolo, por sus diferencias culturales en parte, pero sobre todo por su marginalidad laboral y so- 
cial. El inmigrante es entonces excluido, y objeto preferente de violencia, porque es extranjero, porque procede de un país pobre y porque forma parte de las capas más bajas de la sociedad (Grignon, 1993).

Cabe pensar que, para explicar la violencia xenófoba, sea preciso acudir, además, a otros fenómenos más elusivos y de más difícil tratamiento, como la concepción de la alteridad y la diferencia en nuestra cultura, o la cuestión de las identidades, esa disolución de las identidades tradicionales que genera identidades débiles al tiempo que la afirmación de "identidades hiperseguras" (Imbert, 1993) que reaccionan mediante una sobre-afirmación, una sobre-identificación que refleja una violencia reactiva.

\subsection{La violencia anómica.}

Cabe hablar, finalmente, de una forma de violencia que crece en nuestras sociedades, un poco por todos los sitios, y que es distinta de las anteriores formas no tanto en sus manifestaciones como en su origen y su significado. Podríamos denominarla "violencia expresiva", en el sentido de no orientada a fines, que se manifiesta individual y colectivamente. Una violencia ciega, irracional, aparentemente inexplicable, cuyas motivaciones no pueden ser siquiera expresadas por sus protagonistas y, si lo hacen, es bajo formas absurdas que no podemos reconocer. Es una violencia sintomática y no estratégica, pero no por ello menos peligrosa ni menos causante de heridas y malestares sociales.

Hace tiempo que esta violencia ocupa a los especialistas: es la violencia en los estadios de fútbol; el asesinato de mendigos, minorías o iguales como parte del entretenimiento del sábado noche; la destrucción del patrimonio público o privado como aliciente añadido al ocio; todas las formas de la diversión "paroxística", desde la conducción suicida o asesina hasta la violencia contra las personas. Es también esa violencia que sacude periódicamente a los barrios de las grandes ciudades americanas y europeas: la violencia destructiva de las minorías, siempre justificable pero nunca justificada, que tiene por objeto a la policía, los bienes o a otras minorías étnicas, como ha ocurrido en algunos de los grandes disturbios de las ciudades norteamericanas. Es posible que no sea legítimo, desde cierto punto de vista, reunir bajo un mismo título todas esas clases de violencia, pero consideramos que comparten, en todos los casos, un común denominador: violencia sin objetivos, que no violencia sin causas.

Podríamos clasificar también estos fenómenos como "violencia anómica", como propone Dahrendorf (1990 y 1998) recuperando el viejo concepto de Durkheim, para recordar su origen social, pero desligado de las formas más conocidas del conflicto social y de la desvia- 
ción, tal y como han sido estudiadas: "Los conflictos no se presentan como líneas de batalla en una guerra revolucionaria, o incluso como una lucha de clases democrática, sino como anomia" (1990: 192). El malestar, los múltiples malestares sociales y culturales no encuentran ya cauce para su expresión. Desligados e inconscientes de su origen, incapaces de encontrar expresión legítima y traducirse en formas de acción colectiva en el terreno social, se manifiestan como violencia ciega, mecanismos de afirmación de una identidad difusa, pero no por ello menos necesitada de afirmación.

Manifestada bajo la forma de violencia asocial o antisocial, ha de ser considerada como violencia social, pues expresa un sentimiento, "aunque sea de impotencia", habla un lenguaje, "aunque sea secreto e inarticulado" (Imbert, 1992: 23), con el fin de imponer su presencia, de obligar a su escucha. Sin duda, esta violencia implica, cuanto menos una relación problemática con la propia identidad y con la ley, al mismo tiempo que con el otro, pero implica sobre todo un deseo de visibilidad social. Es finalmente, por éstos y por otros motivos, la violencia que expresa mejor el carácter de nuestro tiempo.

\section{LOS DESAFÍOS DE LA VIOLENCIA PARA EL TRABAJO SOCIAL.}

No compete al Trabajo Social esencialmente combatir la violencia, ni puede ser ésta su función principal. Sin embargo, en la medida en que el Trabajo Social ocupa una de las parcelas donde con más frecuencia se generan ciertas formas de violencia, y en la medida que forma parte, aun secundariamente, de las respuestas institucionales para el control de la violencia, estamos obligados a pensar sobre la violencia, sobre la que nosotros mismos podemos generar, o sobre la que podemos prevenir con nuestras actuaciones.

\subsection{Comprender la violencia.}

Comprender la violencia en sus dimensiones sociales no es disculparla ni abrir el campo a la tolerancia. La individualización de las responsabilidades tan en boga hoy, que hace al pobre culpable de su pobreza y al violento único responsable de su violencia, es sólo un mecanismo utilizado de forma creciente para justificar la imposición de políticas exclusivamente penales y represivas, para justificar el crecimiento de la población carcelaria y dirigir todos los mecanismos de control social contra los grupos más desfavorecidos. Esta tendencia, que se impone desde los años 80 , ha dado al traste con casi un siglo de avan- 
ces de las ciencias sociales que han tendido a comprender, en el contexto donde se producen, las desviaciones y las violencias.

Comprender la violencia es comprender los conflictos sociales, y comprender a los violentos y a las víctimas en la encrucijada de fuerzas en que actúan. Comprender la violencia es comprender la dimensión colectiva de la violencia, una perspectiva no siempre suficientemente presente entre los trabajadores sociales ni, tal y como comprobamos a diario y confirman algunas comunicaciones presentadas en este mismo Congreso, entre los estudiantes de Trabajo Social. A la propia práctica del Trabajo Social, que se desenvuelve con harta frecuencia entre individuos y familias, se suma el auge del individualismo, constituido como visión única del mundo y valor central de nuestra cultura, reforzando así esta tendencia.

Comprender la violencia es comprender, además, el papel que el Trabajo Social juega en el entramado de la violencia en un doble sentido. Por una parte, en tanto que mediador entre el usuario y la organización, el trabajador social puede desarrollar una actuación de control social, paternalista (Sarasa Urdiola, 1993), burocratizada, de mera respuesta a las necesidades en función de los recursos (Guillen Sádaba, 1993), más atenta a administrar esos recursos escasos que al desarrollo de la autonomía y la potenciación de las capacidades de los usuarios. Puede ejercer, además, una función exclusivamente normalizadora, una forma de violencia, condicionando su intervención al cumplimiento de ciertas normas o excluyendo en la práctica a determinados colectivos. Por otra parte, en tanto que trabaja frecuentemente con aquellos colectivos que están en situación de pobreza y exclusión social, el trabajador social se halla inmerso, y por tanto adquiere alguna forma de compromiso, con el conjunto de las políticas dirigidas a facilitar su inserción o su mero control social.

Comprender la violencia es, tiene que ser también, pensarnos a nosotros mismos como sujetos y objetos de violencia que somos; y entender la ambiguiedad esencial de nuestras ideas y nuestros sentimientos frente a la violencia. Una ambigüedad que nos hace valorar y temer, consentir y rebelarnos, justificar y repudiar unas u otras manifestaciones de la violencia.

\subsection{Prevenir la violencia.}

La desigualdad y la injusticia social son al mismo tiempo manifestaciones de la violencia y factores generadores de violencia. Algunas personas que están en esta situación pueden pasar a actuaciones violentas ante la falta de expectativas y el rechazo que dicha situación produce. Su estigmatización previa no puede sino reforzar el fenóme- 
no. La dificultad en el acceso real a los recursos, a los servicios, la actuación paternalista por parte de las instituciones y los profesionales agravan esa situación y no favorecen el desarrollo de la persona, sino una situación permanente de dependencia, y por tanto de sumisión, lo que se convierte en un factor reforzador de la violencia.

En esta situación no sirve actuar solo a posteriori, es preciso prevenir, actuando de un modo conjunto desde la sociedad y la comunidad donde las personas conviven. En estos casos, es fundamental canalizar esa violencia para buscar alternativas a la situación, y desarrollar estrategias que permitan buscar su propio desarrollo, fomentando el asociacionismo, desarrollo de lazos sociales dirigidos a la inclusión social.

Prevenir la violencia en el ámbito familiar, contra las mujeres y los niños, pero también contra los mayores e, incluso, aunque minoritaria, contra los hombres, con sus secuelas de sufrimiento, infravalorización de las víctimas y reproducción de los comportamientos violentos, es hoy uno los retos para el Trabajo Social. Se trata de descubrirla antes de que se produzca y abordar la situación sin generar más violencia. Aunque difícil, es preciso plantear fórmulas para recuperar al violento, evitando que cause daño de nuevo. Pero es preciso, sobre todo, ayudar a las víctimas a reconstruir un proyecto de vida y a recuperar su dignidad, su autoestima. La prioridad del trabajo con los menores, víctimas directas o indirectas de la violencia, es una tarea preventiva esencial: se trata de evitar que las víctimas de hoy se conviertan en maltratadores mañana.

Los conflictos en la convivencia existen, cómo abordarlos para que no desemboquen en violencia es una tarea fundamental. La prevención es el mejor sistema y el primer paso; el segundo, el desarrollo de estrategias de resolución de conflictos, de negociación en casos de rupturas, de mediación familiar. Hay aquí un enorme campo de actuación que apenas si se ha desarrollado en España. Abordar las situaciones de conflicto trabajando con la familia en su conjunto, con métodos de trabajo en grupo, y analizar los factores del entorno que pueden estar incidiendo en la aparición de los conflictos o de la violencia es clave para evitarla y abordarla.

La inmigración está planteando hoy retos importantes y apenas si hemos comenzado a preparar nuestras respuestas. La actuación prioritaria con los inmigrantes se ha de centrar en atender sus necesidades más urgentes, facilitando su acceso a los recursos precisos para favorecer su integración. Una parte importante de los inmigrantes tiene que resolver los problemas básicos del trabajo, el acceso a la vivienda, la atención sanitaria, la escolarización de los menores, el aprendizaje de la lengua, etc. (Herrera, 1999). Pero, además, es preciso plantear, tam- 
bién en esta primera fase, la necesidad de abordar la tarea con herramientas nuevas. El desconocimiento de sus culturas y valores, el miedo a lo desconocido, la rigidez en el cumplimiento de las normas limitan la actuación profesional con estos colectivos.

Por otra parte, es preciso trabajar desde la comunidad, favoreciendo los valores de la comprensión y la tolerancia, mediando en los conflictos que necesariamente se generan en la convivencia y facilitando la participación social de estos colectivos. Solo a partir del conocimiento mutuo se pueden desarrollar lazos sociales y pautas para la convivencia pacífica. La segregación residencial y social, y el consiguiente aislamiento de los inmigrantes son caldos de cultivo para el desarrollo de distintas formas de violencia.

Otro de los ámbitos de actuación es la prevención de la violencia en los jóvenes, tanto en la escuela como en la calle; una realidad que parece preocupar mayoritariamente, pero donde se desarrollan pocas actuaciones preventivas. En este caso, es preciso diagnosticar la situación no sólo del joven o menor aisladamente, sino también de las circunstancias familiares, del sistema educativo y del grupo de iguales. La violencia puede responder a múltiples fenómenos y, si no se abordan todos, estaremos culpabilizando al menor/joven, sin dar una respuesta real a la situación. La actuación debe ser conjunta, desde el medio escolar y los Servicios Sociales, y se debe abordar con actuaciones dirigidas, además, al barrio o comunidad, es decir, desde la calle (VV.AA., 2001)

\subsection{Oponerse a la violencia.}

Comprender la violencia es permitir un acercamiento racional a la violencia, una conducta ambivalente desde el punto de vista de la racionalidad, que posibilita actuaciones preventivas de la violencia. Oponerse a la violencia es, sobre todo, negar legitimidad a las estrategias violentas, mantener que sólo son admisibles formas no violentas de resolución del conflicto. Si se rechaza la violencia, pero se consiente su validación como estrategia para la consecución de los fines sociales, la violencia encontrará legitimidad añadida.

No disponemos de los medios para erradicar la violencia, todas las manifestaciones de violencia, es cierto, pero las sociedades modernas han sabido encontrar algunos mecanismos capaces de paliar las formas más opresivas de la violencia: el contrato, el sometimiento a las normas consensuadas, la ciudadanía, la promoción del igualitarismo, son viejos ideales modernos nunca universalizados, restringidos al ámbito de algunos grupos y de las naciones que los inventaron, en detrimento de la mayor parte del mundo. El gobierno de la otra globalización 
ha de pasar, necesariamente, por una extensión de esas conquistas y de los mecanismos para defenderlas, frente a la voracidad de las clases y los Estados objetivamente interesados en el desorden de la violencia.

Es posible, quizá, incorporar a las conquistas de la modernidad un ámbito no moderno de tratamiento de la violencia, tan antiguo como la violencia y la humanidad mismas. Walter Benjamin, víctima de una de las oleadas más violentas que sacudieron a la historia del siglo XX, escribió en un texto de 1921:

"Pero, ¿es acaso posible una resolución no violenta de conflictos? Sin duda lo es. Las relaciones entre las personas privadas ofrecen abundantes ejemplos de ello. Dondequiera que la cultura del corazón haya hecho accesibles medios limpios de acuerdo, se registra conformidad inviolenta. $Y$ es que a los medios legítimos e ilegítimos de todo tipo, que siempre expresan violencia, puede oponerse los no violentos, los medios limpios. Sus precondiciones subjetivas son cortesía sincera, afinidad, amor a la paz, confianza y todo aquello que en este contexto se deje nombrar (...) Posiblemente, el mejor ejemplo de ello, el de más alcance, sea la conversación como técnica de acuerdo civil. En la conversación, no sólo la conformidad no violenta es posible, sino que el principio de no utilización de la violencia se debe expresamente a una circunstancia significativa: la no penalización de la mentira. Quizá no haya habido en el mundo legislación alguna que desde su origen la penalizara. De ello se desprende que existe, precisamente en la esfera de acuerdo humano pacífico, una legislación inaccesible a la violencia: la esfera del 'mutuo entendimiento' o sea, el lenguaje." (1996: 34)

\section{BIBLIOGRAFÍA}

ÁLVAREZ URÍA, F. (1989): “Sociologías de la cárcel”, Archipiélago, El peso de la Justicia/2, n 3, 83-97.

BAUDRILLARD, J. (1991): La transparencia del mal. Ensayo sobre fenómenos extremos. Anagrama, Barcelona.

BAUMAN, Z. (2002a): "Guerras de reconocimiento en la frontera planetaria", Claves de razón práctica 120, marzo 2002, 4-8.

BAUMAN, Z. (2002b): "Los nuevos intocables", El País, 10 de febrero.

BECK, U. (2001): "Vivir nuestra propia vida en un mundo desbocado: individuación, globalización y política", en Giddens, A. y Hutton, W. (eds.): En el límite. La vida en el capitalismo global, Tusquets, Barcelona, 233-246. 
BENJAMIN, J. (1996): Los lazos del amor. Psicoanálisis, feminismo y el problema de la dominación, Piados, Barcelona.

BENJAMIN, W. (1998): "Para una crítica de la violencia" (1921), en Para una crítica de la violencia y otros ensayos. Iluminaciones IV, Taurus, Madrid.

BOURDIEU, P. (1999): Meditaciones pascalianas, Anagrama, Barcelona.

BOURDIEU, P. (2000): La dominación masculina, Anagrama, Barcelona.

DAHRENDORF, R. (1990): El conflicto social moderno. Ensayo sobre la política de la libertad, Mondadori, Madrid.

DAHRENDORF, R. (1998): Ley y orden, Civitas, Madrid.

FOUCAULT, M. (1979): Microfísica del poder, La Piqueta, Madrid.

FOUCAULT, M. (1992): Vigilar y castigar, Siglo XXI, Madrid.

FREUD, S. (1995): "De guerra y muerte. Temas de actualidad" (1915), Obras Completas, vol.XIV, Amorrortu editores, Buenos Aires.

FREUD, S.(1995) El malestar en la cultura (1930), Obras Completas, vol. XXI, Amorrortu editores, Buenos Aires.

GIRARD, R. (1995): La violencia y lo sagrado, Anagrama, Barcelona.

GRIGNON, CL. (1993): "Racismo y etnocentrismo de clase",Archipiélago 12, 23-28.

GUILLÉN SÁDABA, E. (1993): "La burocratización del Trabajo Social en intervención social”, Cuadernos de Trabajo Social 6, Universidad Complutense de Madrid, 181-193.

HERRERA, E. (1999): “Minorías étnicas y exclusión social”, en Tezanos, J.F. (ed.): Tendencias en desigualdad social, Sistema, Madrid, 583-613.

HOBBES, TH. (1979): Leviatán, Madrid, Editora Nacional, Madrid.

HURTADO, J. (2001): "La infancia en un mundo desbocado", Alternativas 8.

IMBERT, G. (1992): Los escenarios de la violencia, Icaria, Barcelona.

IMBERT, G. (1993) "El sujeto europeo y el otro", Archipiélago 12, 46-51.

LIPOVETSKY, G. (1991): El crepúsculo del deber. La ética indolora de los nuevos tiempos democráticos, Anagrama, Barcelona.

RAMONEDA, J. (2001): "Sobre las causas de la violencia. Las relaciones entre nihilismo y religión”, en EL PAÍS, 3/10/2001.

SARASA URDIOLA, S. (1993): El servicio de lo social, Ministerio de Asuntos Sociales-INSERSO, Madrid.

SENNETT, R. (2001): "La calle y la oficina: dos fuentes de identidad", en Giddens, A. y Hutton, W. (eds.): En el límite. La vida en el capitalismo global, Tusquets, Barcelona, 233-246.

VIRILIO, P. (1997): Un paisaje de acontecimientos, Paidós, Buenos Aires.

WACQUANT L. (2000): Las cárceles de la miseria, Alianza, Madrid.

VV.AA. (Equipo de Educadores de Calle, Cáritas diocesana de Málaga) (2001):

"Educación de calle; una experiencia de trabajo con jóvenes", Documentación Social 124, 323-337. 